\title{
Gendered Speech in Social Context: Perspectives from Town and Gown
}

\author{
Reviewed by John Macalister
}

\author{
Gendered Speech in Social Context: Perspectives from Town and Gown \\ Edited by Janet Holmes \\ Victoria University Press, Wellington, 2000 \\ RRP: \$39.95
}

Our understanding of issues surrounding gender and language has come a long way since the early 1970s. Awareness of sexist language use has been heightened, and such use challenged, generally successfully. Gender-based boundaries have been broken down in many areas, so that the visibility of women in previously male-dominated domains is far greater than it was twenty-five or thirty years ago. Yet few would suggest that the goal of gender equity has been achieved. This book marks our progress along the road to that objective, and suggests ways of moving ahead.

In one sense the essays in this volume, which represent a selection of papers presented at New Zealand's first-ever Language and Gender Symposium, held at Victoria University of Wellington in late 1999, are a celebration of the developments in language/gender studies over the last twenty-five years. This is particularly so in the first section, (The Gown Perspective), which presents the latest academic research into language/gender. Gender is now being viewed as a social construct rather than an essential sex-determined difference. The deficit model of women's language behaviour is no longer dominant; women are seen to be driving linguistic innovation, as Anne Pauwels demonstrates in 'Inclusive language is good business'. Indeed, Margaret A. Maclagan's analysis of New Zealand English speech data suggests that women, in New Zealand at least, have been leading language change for over a century.

Understandably, given the symposium's venue, this volume is weighted towards research into New Zealand English. To an extent this is a tribute to the vigour and robustness of linguistic research in New Zealand today. However, the book does not focus on New Zealand English alone - British male speech provides the data for an absorbing discussion of men's narratives, and Australian English is well-represented. Nor is the book restricted to varieties of English. Miriam Meyerhoff includes Malo, a Vanuatu language, in her discussion of apologies, and Andrew J. Barke looks at changes in second-person pronouns in Japanese. Uta Lenk examines the language of German job advertisements, in the process raising interesting 
questions about the use of gender-neutral terms in languages which employ grammatical genders.

While this volume is to a certain extent a celebration of the road so far travelled, a thread of pessimism and of warning does follow through several of the essays, beginning in the panel discussion section (Town Meets Gown) and picked up again in The Town Perspective, where 'real world' applications and implications of the academic research are considered.

This theme argues that, while research has come a long way in helping us understand language/gender differences, there is a very real danger that the research will be used to justify gender inequity in the workplace. This, it is claimed, is the view transmitted by popular writing in gender studies, by such books as Men are from Mars, Women are from Venus. Stereotypical male features are deemed to be more effective in the work place, so that negative, disempowering connotations are ascribed to features considered female.

Of course, as the contribution from Victoria University of Wellington's Language in the Workplace Project clearly indicates, it is naïve to claim that women do this and men do that. Linguistic behaviour exists along a continuum, and an individual's repertoire contains both 'male' and 'female' features. Differences are of degree rather than absolute, which Ann Weatherall's analysis of children's speech well illustrates.

Inevitably, one or two of the contributions do carry a slight air of aux armes, citoyennes although the details of how further change is to be implemented are sometimes imprecise. It would be unreasonable, of course, to expect this volume to be sub-titled Gender Equity in 10 Easy Steps. There are no simple answers, and there exists a tension between the importance attached to individual actions and the case to be made for organisational change. Deborah Jones is a strong advocate of making 'gender trouble' and her essay links neatly with the preceding paper, from Su Olsson, who argues for the telling and valuing of women's narratives in the workplace.

This, after all, is research that can change lives. Jennifer J. Peck, in her essay 'The cost of corporate culture: linguistic obstacles to gender equity in Australian business', illustrates the impact on women of bringing academic research into the workplace.

A major response of women in business to exposure to academic research on gender and language has been relief: they learn that they are not 'deviant', but that their linguistic behaviours are acknowledged as acceptable performances, sometimes indicative of a gendered socialised position.

Nor is it the lives of women alone that can be changed. The use of language as a tool of intervention, as a means of helping men with a history of violence against women to re-examine their behaviour in terms of gender/identity, is presented by one of the three male contributors to this 
collection, Damian O'Neill. While his findings are tentative rather conclusive, they are powerfully suggestive.

As with any multi-authored work, there is something for everyone in this volume. One or two of the contributions, such as Jennifer Coates' discussion of male narrative, may incline you to discreetly recording friends' conversations for later analysis. Others may heighten sensitivity towards language practices that discriminate, and some may trigger a resolve to address such practices. All of these are positive responses to the contents of this book. For anyone interested in issues of language/gender, then, this volume is an important survey of current thinking in this field. 